\title{
Irinotecan/Panitumumab Regimen
}

National Cancer Institute

\section{Source}

National Cancer Institute. Irinotecan/Panitumumab Regimen. NCI Thesaurus. Code

C153481.

A chemoimmunotherapy regimen consisting of irinotecan and panitumumab that can be used for the treatment of colon cancer. 